\title{
Element Mis-identification in X-ray Crystallography: A Series of Case Studies
}

\author{
James P. Donahue. Tulane University
}

X-ray crystallography is sometimes described as a definitive technique in identifying a compound. The certainty it offers is really restricted to a description of atom connectivity, as opposed to atom identity, because elements with similar atomic number have similar diffracting power. In this talk, a series of examples are considered in which coordination compounds of the transition metals are incorrectly formulated on the basis of a crystal structure. First, a set of reports describing the syntheses and structures of $\left[\mathrm{MCl}_{2}\right.$ (diazadiene) $](\mathrm{M}=\mathrm{Cr}, \mathrm{Mo}, \mathrm{W})$ complexes is reassessed in the context of known chemistry of low-valent Group VI metal complexes, crystallographic trends such as $\mathrm{M}-\mathrm{Cl}$ bond lengths and unit cell volumes, and calculated metal-ligand bond lengths. Crystallographic data and computational results are inconsistent with any of these species being second or third row transition metal complexes. The crystallographic information files accompanying the $\left[\mathrm{MCl}_{2}\right.$ (diazadiene) $](\mathrm{M}=\mathrm{Mo}, \mathrm{W})$ published structures reveal that the metal atoms were refined with partial site occupancy factors $(0.775$ for Mo; 0.4005 and 0.417 for $\mathrm{W})$, the effect of which was to produce lighter-element behavior and better refinement in accord with the metal atoms' correct identity, which is $\mathrm{Zn}^{2+}$. Divalent zinc originates from zinc metal employed as a reducing agent. A similar case involving $\left[\left(\mathrm{Me}_{3} \mathrm{P}\right)_{2} \mathrm{ZnCl}_{2}\right]$ misidentified as $\left[\left(\mathrm{Me}_{3} \mathrm{P}\right)_{2} \mathrm{MoCl}_{2}\right]$ is noted. A third case of element misassignment involves a tetrametallic species, $\left[\mathrm{M}\left({ }^{i} \operatorname{Pr}_{2} \mathrm{Pipdt}\right)\right]_{4}\left[\mathrm{BF}_{4}\right]_{4} \quad\left({ }^{i} \operatorname{Pr}_{2} \mathrm{Pipdt}=\right.$ diisopropylpiperazine-2,3-dithione), that is created by treatment of $\left[\mathrm{MoOCl}\left({ }^{i} \operatorname{Pr}_{2} \mathrm{Pipdt}\right)_{2}\right]^{+}$with $\mathrm{AgBF}_{4}$. The metal atom is identified as $\mathrm{Mo}^{1+}$, but a variety of chemical considerations is strongly indicative of $\mathrm{Ag}^{+}$as the more chemically plausible metal ion. Finally in our own work, attention is given to considerable confusion caused by the inability to distinguish $\mathrm{Cl}^{-}$from $\mathrm{SH}^{-}$as a ligand in $\mathrm{Cu}^{1+}$ complexes on the basis of crystallography. Offered in conclusion are thoughts on some preemptive practices that guard against element mis-identification in the crystal structure determination process. 